\title{
O Estado entre o alguém e o ninguém
}

\author{
The State between somebody and nobody
}

João Francisco Cortes Bustamante ${ }^{1}$

\begin{abstract}
Resumo
A revolução técnico-científica da década de 1970 e as consequências da crescente transformação tecnológica ocasionaram um reposicionamento da relação entre o Estado e a economia. A formação de conglomerados e de maior integração entre produção industrial e finanças expõe uma renovação das empresas para ampliar a área de atuação da produção e do consumo. O Estado direcionado para atender ao público volta-se para o setor econômico privado em uma reversão do princípio primeiro da política. A concepção política de Hannah Arendt de um Estado e um governo concebidos para o alguém transformado para o ninguém é a referência principal para compreender como a tecnologia é o laço entre política e economia. A perspectiva de Paul Virilio sobre a velocidade é o princípio filosófico como condição para que a tecnologia direcione o capital de modo a desequilibrar a relação entre política e economia. O artigo propõe o Estado dependente da economia por meio da tecnologia em que a economia supera a política.
\end{abstract}

Palavras-chave: Estado. Tecnologia. Velocidade. Capital.

\begin{abstract}
The technical-scientific revolution of the 1970 s and the consequences of the increasing technological transformation led to a repositioning of the relationship between the State and the economy. The formation of conglomerates and greater integration between industrial production and finance exposes a renewal of companies to expand the area of production and consumption. The State directed towards serving the public turns to the private economic sector in a reversal of the first principle of politics. The political conception of Hannah Arendt of a State and a government conceived for somebody transformed into nobody is the main reference for understanding how technology is the ties between politics and economics. The perspective of Paul Virilio on speed is the philosophical principle as a condition for technology to drive capital to unbalance the relationship between politics and economics. The article suggests the State dependent on the economy through technology in which the economy surpasses politics.
\end{abstract}

Keywords: State. Technology. Speed. Capital.

\footnotetext{
${ }^{1}$ Mestre em Governo e Cultura das Organizações pela Universidade de Navarra (2008) e Mestrado em Diplomacia e Relações Internacionais pela Escola Diplomática/MAEC (2010). Atua na área de Economia, Relações Internacionais, Política e Diplomacia. Sócio-fundador da consultoria Psicotur. E-mail: joao.bustamante@edu.pucrs.br
} 


\section{Introdução}

O presente trabalho orienta-se no período histórico da segunda metade do século XX por meio da definição do historiador Eric Hobsbawm, em sua obra Era dos Extremos, entre a denominada Era de Ouro (1950-1973) e o Desmoronamento (1973-1991). A Era de Ouro ancorava-se "na mais avançada e muitas vezes esotérica pesquisa científica” (HOBSBAWM, 1995, p. 260). Desse modo, a revolução técnicocientífica da década de 1970 corresponde às transformações na pesquisa científica, na tecnologia e na produção industrial de forma que "A indústria e mesmo a agricultura pela primeira vez ultrapassavam decididamente a tecnologia do século XIX” (HOBSBAWM, 1995, p. 260). As empresas restritas à produção de um bem com vistas ao consumo convertem-se em conglomerados em que expandem as áreas de atuação e incorporam setores agrícolas e serviços. Torna-se comum alguns termos como agronegócio ou cooperativas agrícolas em que a racionalização da produção, expansão dos negócios e ajustamento entre negócios, consumidor e consumo aprofundam-se de modo contínuo e veloz já que “A grande característica da Era de Ouro era precisar cada vez mais de maciços investimentos e cada vez menos gente, a não ser como consumidores" (HOBSBAWM, 1995, p. 262). Como consequência, empresas transnacionais e o setor de serviços são centrais na integração regional e na globalização.

A relação entre o setor agrícola, setor industrial e o setor de serviços torna-se comum e não diferenciada em que por meio dos conglomerados a integração empresarial passa a ser vertical e não horizontal de modo que "A integração dos processos de produção em massa com os de distribuição em massa numa só organização deu origem a um novo tipo de empresa capitalista” (ARRIGHI, 1996, p. 248). Essa verticalidade permite agilidade e adaptabilidade por meio de um conglomerado produzir, vender e financiar de modo concomitante a fim de se inserir no mercado produtor e no mercado consumidor ao mesmo tempo e em qualquer parte do mundo porque "[...] as empresas verticalmente integradas passaram a desfrutar de vantagens competitivas decisivas em relação às empresas formadas por uma só unidade ou mesmo às empresas de unidades múltiplas, menos especializadas" (ARRIGHI, 1996, p. 249). Esse processo adquire entre os anos de 1970 e 2000 uma crescente prática em que os serviços, são tão importantes quanto os bens produtivos e, no século XXI, já é uma prática consolidada. 
A revolução técnico-científica da década de 1970 é acompanhada, assim, pela formação dos conglomerados em conjunto com o impulso dado para que o Estado seja cada vez mais aliado do capital e do incentivo aos investimentos em "uma "economia mista", que ao mesmo tempo tornou mais fácil aos Estados planejar e administrar a modernização econômica e aumentou enormemente a demanda" (HOBSBAWM, 1995, p. 264). O Estado, como entidade política e administrativa de um país, oscila entre as concepções e práticas de um Estado interventor ou um Estado liberal, principalmente no período do Desmoronamento (1973-1991), pois “O futuro estava na "economia mista”" (HOBSBAWM, 1995, p. 268). Essa oscilação de qual tipo de Estado direciona um país não impede a aliança estreita entre o Estado e o capital em que se perverte a atenção da política do público para o privado, especificamente para o setor econômico privado.

$\mathrm{O}$ artigo lida com o Estado in lato sensu, pois, ainda que a filosofia políticoeconômica a partir do Estado seja relevante, não se privilegia nenhum escopo de argumento e análise tanto devido à complexidade do tema quanto às especificidades correspondentes a cada país. Dessa forma, o Estado será considerado genericamente como a entidade política e administrativa de um país e no modo como se relaciona com o capital. Igualmente, se privilegia a noção de que "O capital é um fator de produção que difere bastante em relação aos outros fatores, especialmente quando se refere ao trabalho" (FELDENS, 1996, p.152) ao ponto que "[...] a própria natureza do capital se transformou radicalmente (do capital fundiário, baseado na propriedade da terra do século XVIII, ao capital imobiliário, industrial e financeiro do século XXI)" (PIKETTY, 2014. p. 48). Desse modo, o capital é fator de produção para bens e serviços em consonância com o trabalho e a tecnologia.

O artigo privilegia a concepção política de Hannah Arendt de um Estado e um governo concebidos para o alguém transformado para o ninguém, buscando compreender como a tecnologia constitui o laço entre política e economia. Para isso, a perspectiva de Paul Virilio sobre a velocidade será o princípio filosófico que, tomado como condição, possibilitará que a tecnologia direcione o capital de modo a desequilibrar a relação entre política e economia. A compreensão de velocidade de Paul Virilio é privilegiada no artigo como proposta filosófica e analítica para a justificativa transformacional enquanto a aceleração é concebida estritamente como o meio de expansão da velocidade. Desse modo, o artigo propõe o Estado como 
dependente da economia por meio da tecnologia, situação em que a economia supera a política, pervertendo o alguém em favor do ninguém.

\section{O Estado}

Hannah Arendt lida com a política na noção de diferença entre o espaço público e o espaço privado. O espaço público como o espaço de diálogo entre as pessoas, entre os seres humanos que agem e interagem na concepção primeira da polis grega é também o espaço de inserção do Estado (ARENDT, 2010). A entidade político-administrativa denominada Estado, emergida do social, age no espaço público com implicações tanto para o espaço público quanto para o espaço privado. Desse modo, o Estado é o meio de relação para que as pessoas no agir do espaço público participem da política.

A política como o agir das pessoas no espaço público adquire nomeação, pois é sempre alguém que age. Este alguém nasce, age e renasce constantemente no espaço público em uma expressão de quem e, não, do que consiste a política. A pergunta e a resposta no agir humano na política do espaço público é mostrar e emergir sempre o alguém e, por isso, o embate, a persuasão e o diálogo são constituintes do espaço público e da política. É o alguém que percorre a política desde Platão até Karl Marx em uma tradição (ARENDT, 2014).

Essa participação na política é perdida quando o Estado e o governo se voltam para o ninguém como resultante de uma crescente burocracia. Os sinais ocorrem a partir da Revolução Industrial no século XIX quando a relação entre os meios de produção, as pessoas e o Estado padecem de transformações significativas, mas é o Estado totalitário do século XX a expressão primeira dessa subversão das relações públicas e privadas. O Estado totalitário apresenta o absoluto de uma pessoa como mandante e comandante do espaço público em que a direção do governar sai do alguém e se direciona para o ninguém. Como consequência, na representação do mandante e comandante de um ser só no Estado totalitário, cada pessoa constituinte absolutiza o espaço privado no espaço público em que o alguém passa a ser ninguém. De outro modo, a máquina do Estado para funcionar requer a absolutização do espaço público para que o alguém seja suprimido e, assim, o ninguém prevaleça em um processo de estrito controle, organização e negociação constantes. Ao retirar a presença do alguém porque o Estado totalitário governa um 
espaço constituído por ninguém, cada ser nominado como alguém se encontra subjulgado como ninguém por meio de números, de símbolos ou de marcas. Por isso, o alguém perece para o ninguém nascer:

Mas o que é desconcertante no sucesso do totalitarismo é o verdadeiro
altruísmo dos seus adeptos. [...] para o assombro de todo o mundo
civilizado, estará até disposto a colaborar com a própria condenação e
tramar a própria sentença de morte, contanto que o seu status como
membro do movimento permaneça intacto. [...] a identificação com o
movimento e o conformismo total parecem ter destruído a própria
capacidade de sentir, mesmo que seja algo tão extremo como a tortura ou
o medo da morte (ARENDT, 1989, p 357-358).

Uma vez constituído esse espaço do ninguém, cujo perecer também ocorre, cabe ao governo de um Estado totalitário manter a máquina em funcionamento. A exemplificação de máquina como constituinte do modus operandi governamental concebe-se que não foi abandonado após o período do Estado totalitário. Ao contrário, conquanto o Estado totalitário esteja demarcado historicamente, se institui a mudança da atenção do Estado para com o público em uma alteração do alguém para o ninguém quando da transformação das condições econômicas da década de 1970, pois “É óbvio que a finança internacional tem um impacto profundo na economia global" (GILPIN, 2001, p. 7) ${ }^{2}$. Um novo momento emergia entre a Era de Ouro (1950-1973) e o Desmoronamento (1973-1991) em que "A reestruturação do capitalismo e o avanço na internacionalização da economia foram fundamentais" (HOBSBAWM, 1995, p. 265). Como consequência, um dos pontos em destaque é a mudança ocorrida na configuração do Estado como organização administrativopolítica: "E se pode debater prolongadamente e com proveito o governo de Ninguém, que é o que de fato significa a forma política conhecida como bureaucracia” (ARENDT, 1999, p. 313). De outro modo, o Estado mantém a perspectiva de máquina e engrenagem na burocracia organizacional, porém, à medida que a revolução técnico-científica da década de 1970, a formação dos conglomerados e o capital catalisam a economia, o Estado transforma-se em um crescente governo de ninguém no aparato burocrático.

Essa burocracia do governo de ninguém sustenta-se na tecnologia e, mais especificamente, no controle exercido sobre o espaço público. A tecnologia é o vínculo entre política e economia, entre o Estado e o setor econômico privado, mas

\footnotetext{
${ }^{2}$ Tradução do autor. O original é "It is obvious that international finance has a profound impact on the global economy".
} 
requer, para isso, velocidade para que a tecnologia direcione o capital. Cabe compreender a velocidade como princípio filosófico para que se permita absorver o Estado direcionado a alguém se tornar um governo de ninguém a fim de expor como a economia supera a política por meio da dependência do Estado para com a tecnologia em uma tendência crescente do ninguém em detrimento do alguém.

\title{
Velocidade
}

A história da filosofia contempla Zenão de Eleia (490 a.C. - 430 a.C.), filósofo pré-socrático, como uma das primeiras referências sobre velocidade em conjunto com princípios filosóficos como tempo, movimento, aceleração e espaço. Essas temáticas perpassam pensadores como Aristóteles, Platão, Plotino, Agostinho de Hipona, Immanuel Kant, Martin Heidegger, para citar apenas alguns, de modo a se manter centrais como objeto de estudo e de exercício do pensamento. Igualmente, áreas como física, sociologia, história, arquitetura, artes e outras também lidam com estudos sobre esses assuntos.

Nesse escopo, o arquiteto e urbanista Paul Virilio (1932-2018) emerge como um dos principais pensadores sobre a velocidade ou da denominada dromologia ${ }^{3}$ na segunda metade do século XX. Em um amplo espectro de suas obras, a velocidade aparece como linha mestra de estudo e análise do modo como a velocidade se insere e perpassa a sociedade, a política, a economia e o comportamento humano. Destarte, de modo inicial, a compreensão sobre a velocidade requer o pressuposto de espaço e tempo. Em essa dimensão espaço e tempo institui-se uma relação entre velocidade e tempo em que a velocidade é um vetor que não tem como limite o espaço físico:

\begin{abstract}
A manobra que consistia ontem em ceder terreno para ganhar Tempo perde todo sentido; na atualidade, o ganho de Tempo é exclusivamente de vetores, e o território perdeu suas significações em benefício do projétil. $\mathrm{Na}$ verdade, o valor estratégico do não-lugar da velocidade definitivamente suplantou o do lugar, e a questão da possessão do Tempo renovou a da apropriação territorial (VIRILIO, 2006, p. 119).4
\end{abstract}

\footnotetext{
3 Sobre a dromologia em Paul Virilio, consultar ROCHA, Maria Carolina dos Santos. Da dromologia: Paul Virilio e a poética do movimento. 2001. Tese (Doutorado em filosofia) Universidade Federal do Rio Grande do Sul, Porto Alegre, 2001.

4 Tradução do autor. O original é "La maniobra que consistía ayer en ceder terreno para ganar Tiempo pierde todo sentido; en la actualidad, la ganancia de Tiempo es exclusivamente cuestión de vectores, y el territorio perdió sus significaciones en provecho del proyectil. De hecho, el valor estratégico del no-lugar de la velocidad definitivamente suplantó el del lugar, y la cuestión de la posesión del Tiempo renovó la de la apropiación territorial”.
} 
O espaço não parece ser mais o limite, ou seja, o espaço na compreensão física, como limítrofe, é desafiado pela velocidade e pelo tempo. As relações entre espaço, tempo e velocidade são, com isso, modificados:

[...] a localização geográfica parece ter perdido definitivamente seu valor estratégico e, ao contrário, esse mesmo valor é atribuído à deslocalização do vetor, de um vetor em movimento permanente, seja esse aéreo, espacial, submarino ou subterrâneo, pouco importa, o único que conta é a velocidade do móvel e a indetectabilidade de seu percurso (VIRILIO, 2006, p. 120). 5

Desse modo, há um predomínio da velocidade e, não, do tempo:

Hoje em dia, é preciso reconhecer que os sistemas e os instrumentos de medida são menos cronométricos que cinemométricos; não é mais o tempo de passagem que serve de padrão para o espaço percorrido, mas a velocidade, a distância-velocidade, isso se tornou a medida, a dimensão privilegiada do espaço como do tempo (VIRILIO, 1984, p. 70). 6

Nessa dimensão privilegiada, a distância-velocidade, a revolução técnicocientífica da década de 1970 insere-se como primordial para que empresas possam multiplicar o capital a fim de que o capital antes produtivo dos bens seja cada vez mais um capital financeiro. Ciência e capital são aliados, portanto, em uma dinâmica que desafia a razão e, consequentemente, a ética:

[...] a ciência "pós-moderna" se compromete, a partir de agora, com um novo tipo de competição completamente delirante: uma corrida dos resultados-limites nos campos da robótica ou da engenharia genética que impele, por sua vez, aos diferentes saberes por uma via de um "extremismo pós-científico" que os priva de toda razão (VIRILIO, 1999, p. 12).7

É uma distância-velocidade somada com o técnico-científico, a tecnologia e a robotização impulsionadas no período do Desmoronamento (1973-1991):

O impacto da tecnologia gerada pela alta pesquisa na indústria civil provavelmente só se tornou substancial nas Décadas de Crise depois de 1973, quando se deu a grande inovação na tecnologia de informação e na

\footnotetext{
5 Tradução do autor. O original é "[...] la localización geográfica parece haber perdido definitivamente su valor estratégico y, a la inversa, ese mismo valor es atribuido a la deslocalización del vector, de un vector en movimiento permanente, ya sea éste aéreo, espacial, submarino o subterráneo, poco importa, lo único que cuenta es la velocidad del móvil y la indetectabilidad de su carrera".

${ }^{6}$ Tradução do autor. O original é "Aujourd'hui, il faut le reconnaître, les systèmes et les instruments de mesure sont moins chronométriques que cinémométriques; ce n'est plus le temps de passage qui sert d'étalon à l'espace parcouru, mais la vitesse, la distance-vitesse, celle-ci est devenue la mesure, la dimension privilégiée de l'espace comme du temps".

7 Tradução do autor. O original é "[...] la ciencia $<<$ posmoderna $>>$ se compromete, a partir de ahora, en un nuevo tipo de competición completamente delirante: una carrera de los resultados-límites en los campos de la robótica o de la ingeniería genética que arrastra, a su vez, a los diferentes saberes por la vía de un $<<$ extremismo poscientífico >> que los priva de toda razón”.
} 
engenharia genética, além de vários outros saltos no desconhecido (HOBSBAWM, p. 265)

As consequências do avanço tecnológico no final do século $\mathrm{XX}$ e intensificadas no século XXI com a intensificação das máquinas e robôs autônomos, por exemplo, alinham-se à velocidade e ao instantâneo e, como consequência, moldam uma nova realidade:

Com a concepção relativista do mundo, é a velocidade da luz que baliza o real, e a luz da velocidade que ilumina a realidade. A velocidade absoluta sucede ao tempo assim como ao espaço constante. A instantaneidade substitui as durações longas, os séculos dos séculos (VIRILIO, 1999, p. 58).

Como consequência, o capital mantém-se multiplicado, mas, a velocidade da multiplicação torna-se essencial. É a produção e o consumo de bens concomitantemente com o mercado financeiro em que o capital requer circular velozmente. As transformações são constantes entre velocidade e circulação:

hoje em dia, certamente mais que nunca, ao alcançar os fixos uma grande importância, a circulação tem uma importância fundamental, entre outras razões pelo fato de que o produto se internacionalizou e, por conseguinte, se distribui por todo o mundo, independentemente de fronteiras e de distâncias. Por outro lado, a necessidade de acumulação se agravou e, por conseguinte, a circulação alcançou um ritmo frenético (SANTOS, 1996, p. 76). ${ }^{8}$

A circulação do produto requer velocidade sem fronteiras em uma dimensão da distância-velocidade em que o capital necessita do incentivo do Estado para ampliar o escopo de atuação, ou seja, do capital produtivo ser também capital financeiro em processo de acumulação. Igualmente, a aceleração compreendida como investimento contínuo e crescente em tecnologia e recursos científicos permite mais velocidade, mais circulação e mais acumulação. É primordial para que o capital multiplicado e o deslocamento do capital possam efetivar-se como investimento, como serviços e como produtos financeiros de que o Estado seja um aliado. Não é casual o efeito para com o Estado, pois "A perda do espaço material resulta em não governar mais que o tempo; o Ministério do Tempo esboçado em cada vetor se realizaria por fim nas dimensões do maior veículo existente, o vetor-

\footnotetext{
8 Tradução do autor. O original é "hoy en día, ciertamente más que nunca, al alcanzar los fijos una gran importancia, la circulación tiene una importancia fundamental, entre otras razones por el hecho de que el producto se internacionalizó y, por consiguiente, ha de distribuirse por todo el mundo, independientemente de fronteras y de distancias. Por otro lado, la necesidad de acumulación se agravó y, por consiguiente, la circulación alcanzó un ritmo frenético".
} 
Estado" (VIRILIO, 2006, p. 125)9.

O Estado é o aliado por excelência do capital para que este seja multiplicado e o seu deslocamento seja efetivado, requerendo, para isso, um modo de vida intenso e direcionado para um ser humano pensado e incentivado a ser autônomo, cuja representação, marca constante da publicidade, é a felicidade. Mais do que isso, esse ser humano autônomo é capitalizado por meio dos instrumentos técnicocientíficos, da tecnologia e da robotização e, consequentemente, perde existência e pertencimento do viver:

Hoje observa-se, ao contrário, o completo abandono e a reversão dessa
relação: o projeto de vida serve ao objetivo de acompanhar o jogo de
aumento, de permanecer ou tornar-se competitivo. Individual e
coletivamente, fantasias de dar forma à vida, e as energias nelas investidas,
se direcionam, cada vez com mais intensidade, à manutenção da
capacidade de aumento. A promessa fundante da Modernidade é quebrada
com isso. Pela imposição da lógica de aumento exaure-se a margem de
ação da autonomia, individual e política (ROSA, 2019, p. XXV).

De modo esquemático, o capital e o Estado se aliam para que o ser humano capitalizado e instrumentalizado pela tecnologia seja o meio pelo qual o capital multiplicado e o deslocamento do capital possam efetivar-se. Além disso, o capital necessita não só o Estado como aliado, mas superar o Estado em suas atribuições legislativas e executivas como, por exemplo, permitir a livre circulação de capitais e integrar os países seja por integração regional seja por cadeias produtivas globais seja por mercados financeiros interconectados. É essencial, para isso, que a dimensão distância-velocidade conceba um ser humano apto e ativo para que viva uma realidade diferente no último quarto do século XX, pois, “[...] surge um sol artificial, uma iluminação de emergência que inaugura um tempo novo: o TEMPO MUNDIAL no que a simultaneidade das ações deve logo prevalecer sobre seu caráter sucessivo" (VIRILIO, 1999, p. 22-23) ${ }^{10}$.

Presencia-se, assim, a crescente iniciativa de transformação de empresas produtivas em conglomerados, a formação do agronegócio e a importância do setor de serviços na economia dos Estados. Integrar o capital produtivo e o capital

\footnotetext{
9 Tradução do autor. O original é "La pérdida del espacio material desemboca en no gobernar más que el tiempo; el Ministerio del Tiempo bosquejado en cada vector se realizaría por fin en las dimensiones del mayor vehículo existente, el vector-Estado".

${ }^{10}$ Tradução do autor. O original é "[...] surge un sol artificial, una iluminación de emergencia que inaugura un tiempo nuevo: el TIEMPO MUNDIAL en el que la simultaneidad de las acciones pronto debería primar sobre su carácter sucesivo”.
} 
financeiro em consonância com a velocidade do capital é essencial para o capital multiplicado e o deslocamento do capital.

\section{Mais ninguém, menos alguém}

A conjunção entre velocidade e capital na representação do capital multiplicado consiste na orientação do setor empresarial em integração com o setor de serviços. Para isso, as multinacionais requerem menores custos, menores barreiras junto com integração regional e acordos de investimentos a fim de multiplicar o capital. O Estado não se torna impeditivo para as ações transnacionais das multinacionais:

Por volta de 1970, quando começou a crise da hegemonia norte-americana,
tal como encarnada na ordem mundial da Guerra Fria, as empresas
multinacionais haviam evoluído para um sistema de produção,
intercâmbio e acumulação, em escala mundial, que não estava sujeito a
nenhuma autoridade estatal e tinha o poder de submeter a suas próprias
"leis" todo e qualquer membro do sistema interestatal, inclusive os Estados
Unidos (ARRIGHI, 1996, p. 74).

Não é casual o fato de o Estado não ser barreira ao capital e às ações transnacionais de que o Estado, principalmente nos países em desenvolvimento, tende a ser cada vez mais direcionado a um processo de reformas administrativas, tributárias, entre outras, a fim de facilitar os investimentos privados e o mercado financeiro. Essa iniciativa adquire ênfases e matizes diversos, principalmente, ao fim do período de Desmoronamento (1973-1991) quando “[...] mais e mais nações buscavam políticas econômicas neoliberais como a desregulamentação e a privatização" (GILPIN, 2001, p. 8) ${ }^{11}$. O Estado incentiva e impulsiona, portanto, o capital a ser multiplicado e ser deslocado em uma estreita aliança entre o Estado, setor público, e o setor privado já que "A relação da economia e da política é interativa" (GILPIN, 2001, p.23).

Esse incentivo do Estado requer o governo de ninguém de modo que a burocracia esteja à mercê dos processos de reformas diversos para que Estado e capital estejam aliados. O cerne não é a necessidade das diversas reformas, mas como o Estado direciona essas reformas menos em benefício do alguém e mais em prol do ninguém. Na linha de Hannah Arendt, ao invés de haver no espaço público

${ }^{11}$ Tradução do autor. O original é "[...] more and more nations have been pursuing neoliberal economic policies such as deregulation and privatization". 
o alguém, o quem do espaço público torna-se ninguém e, o ninguém é simplesmente a burocracia governamental. O governo de ninguém no espaço público abrange desde a tecnologia e o controle exercidos no sentido administrativo, função precípua do Estado como arrecadar impostos ou investir em educação e saúde, quanto no sentido legalista de controle como, na expressão que dá o título ao livro de Michel Foucault, vigiar e punir. O governo de ninguém transforma o alguém em números, algoritmos e estatísticas em que se des-personaliza o alguém em favor do ninguém porque "o capitalismo de vigilância reivindica unilateralmente a experiência humana como matéria-prima livre a ser traduzida em informação comportamental” (ZUBOFF, 2019, p. 14) ${ }^{12}$. De outra forma, o Estado como governo de ninguém se alia ao setor econômico privado de modo que "A política agora é feita no mercado" (SANTOS, 2005, p. 67).

Esse governo de ninguém massivo na organização político-administrativa e no exercício de poder auxilia o capital de modo que o Estado se torne dependente da economia por meio da tecnologia. Em essa senda, a mão de obra recebe formação técnica, especializada, qualificada para estar a par da tecnologia e da robotização inseridas no setor industrial e no setor de serviços. A constante necessidade de adaptar a mão de obra ao conhecimento de novas tecnologias e técnicas reflete-se “[...] no campo da educação continuada, da atividade asseguradora de oportunidades do networking, ou da análise de mercado de trabalho [...]" (ROSA, 2019, p. 347). Tem-se, com isso, uma economia do conhecimento de modo que "o conhecimento é capital - capital intelectual - porque se acumula e pode se armazenar para um uso futuro" (SISON, 2006, p. 225) ${ }^{13}$.

Forma-se quase uma constante, principalmente nos países em desenvolvimento, um índice de desemprego significativo de mão de obra de baixa qualificação enquanto nos países desenvolvidos os índices de desemprego oscilam em patamares baixos à custa do incentivo à imigração. O final do século XX presencia, portanto, o aumento do fluxo de mão de obra internacional por meio da imigração concomitantemente com o alargamento da integração regional. Esse processo impulsiona “[...] tanto na Europa como nos Estados Unidos, o aumento

\footnotetext{
12 Tradução do autor. O original é "Surveillance capitalism unilaterally claims human experience as free raw material for translation into behavioral data".

${ }^{13}$ Tradução do autor. O original é "el conocimiento es capital - capital intelectual - porque se acumula y puede almacenarse para un uso futuro".
} 
das novas divisões entorno das questões migratórias e ao multiculturalismo [...]” (PIKETTY, 2019, p. 576) ${ }^{14}$.

Nesse sentido, a velocidade do capital multiplicado e a velocidade do deslocamento do capital na dimensão da distância-velocidade supera o possível controle do Estado. Igualmente, os seres humanos são impactados pelas transformações contínuas e intensas no modo de trabalhar e pelas tecnologias com consequências físicas e psíquicas já que "O que é singular em nossa era é a escala do impacto global e a taxa de mudança tecnológica. $\mathrm{O}$ desafio de humanizar o processo é, por isso, sem precedente" (KISSINGER, 2001, p. 217) ${ }^{15}$.

O modus operandi do capital multiplicado e do deslocamento do capital reforça hierarquias e diferenças existentes e cria novos abismos sociais. A propulsão veloz do capital como decorrência da mudança tecnológica, constante e contínua, alavanca essas hierarquias e diferenças como, por exemplo, ricos e pobres, diplomados e sem diploma, experiência e sem experiência, entre outros, cujas divisões não são sempre nítidas e simples como aparentam ser porque há “[...] uma superação das mudanças a ritmo geracional por mudanças intrageracionais na estrutura ocupacional e na reposição da força de trabalho" (ROSA, 2019, p. 220). Há um reforço, pois, "O ato de reconhecer e ser reconhecido significa também o poder de reconhecer, de designar o que e quem deve ser reconhecido ou o que é pertinente de ser dito ou não em dado momento em dado campo" (CORTÉS, 2016, p. 102).

Não é à toa que "Trata-se também de pessoas que controlam a aplicação de gigantescos recursos, muito além de sua capacidade de gestão e de aplicação racional" (DOWBOR, 2017, p. 49) de modo que influenciam as ações em relação ao capital em termos financeiros e de investimento produtivo e, consequentemente, a política nacional e a política internacional. Ao mesmo tempo, o abismo sócioeconômico aprofunda-se e se amplia tendo em vista a quantidade dos não reconhecidos, os que se encontram à margem do capital multiplicado e do deslocamento do capital.

A condição do trabalhador muda porque "Existem, por um lado, os que estão estabilizados por um emprego, os que têm carteiras de trabalho, os que estão

\footnotetext{
${ }^{14}$ Tradução do autor. O original é "[...] tanto en Europa como en Estados Unidos, el aumento de las nuevas divisiones en torno a las cuestiones migratorias y al multiculturalismo [...]".

15 Tradução do autor. O original é "What is unique in our age is the scale of the global impact and the rate of technological change. The challenge of humanizing the process is, therefore, unprecedented".
} 
instalados, e, por outro lado, os nômades, que já não estão localizados e que mudam sempre de um trabalho precário a outro" (VIRILIO, 1999, p. 72) ${ }^{16}$. A rotatividade da mão de obra, a precariedade dos empregos, as más condições de trabalho, as doenças advindas do mal-estar contemporâneo, a integração regional, a globalização e a incapacidade do Estado-Nação em lidar com os adventos do fim do século XX e do primeiro quarto do século XXI servem para acelerar a dimensão distância-velocidade na instantaneidade do capital multiplicado e do deslocamento do capital.

As crises financeiras e econômicas tendem a aprofundar-se pela capacidade adquirida pelo capital na dimensão distância-velocidade. Não é casual a série de crises da década de 1990 (México, Tigres Asiáticos, Rússia, Brasil), bem como a crise de 2008. Os conglomerados e a integração setor produtivo e setor de serviços agravam a relação capital e crises ao dependerem cada vez mais do capital multiplicado e do deslocamento do capital. Como consequência, se aprofunda a diferença entre o mercado financeiro e a economia real, um descolamento entre o capital multiplicado e o deslocamento do capital do âmbito financeiro e o capital produtivo dos bens e da situação econômica de cada ser humano, "Isso é, alto crescimento do setor financeiro reduz o crescimento real" (CECCHETTI; KHARROUBI, 2015, p. 25) ${ }^{17}$. Observa-se muitas vezes um crescimento do mercado financeiro em detrimento a uma estagnação ou retrocesso da economia real em que pressiona os conglomerados a integrar capital produtivo e capital financeiro em que este último torna-se continuamente a âncora em momentos de crise econômica.

A necessidade da transformação tecnológico-científica entrelaça a dimensão distância-velocidade com o setor produtivo e o setor de serviços por meio do capital multiplicado e do deslocamento do capital. A sustentabilidade da produção e do consumo tende a estar cada vez mais dependente não só da tecnologia, mas, principalmente, da dimensão distância-velocidade e da velocidade do capital multiplicado e do deslocamento do capital. Por isso, crises econômicas, como as da década de 1990 e das primeiras décadas de 2000, "se alega aos mercados de capitais internacionais terem criado uma rede de interdependência econômica que transformam a natureza das relações internacionais e destroem a independência

\footnotetext{
${ }^{16}$ Tradução do autor. O original é "Existen, por un lado, los que están sedentarizados por un empleo, los que tienen lugares de inscripción, los que están alojados, y, por otro, los nómadas, que ya no están ubicados y que cambian de un trabajo a otro siempre precario".

17 Tradução do autor. O original é "That is, higher growth in the financial sector reduces real growth".
} 
econômica e política dos estados-nação" (GILPIN, 2001, p. 36) ${ }^{18}$ de modo que não há barreiras para o capital multiplicado e o deslocamento do capital na dimensão distância-velocidade.

\section{Conclusão}

O Estado alia-se ao capital em um processo constante e crescente de tornar a organização político-administrativa em uma máquina, cuja burocracia é um governo de ninguém. Para isso, o espaço público do alguém é suprimido pelo governo de ninguém em uma transformação do Estado e do governo como dominantes do espaço público. Esse domínio interno e externo ao Estado e ao governo ocorre por adesão à tecnologia e ao controle de forma a ser crescente e constante o Estado aliado do capital. Essa aliança demanda suprimir o alguém em prol do ninguém para que cada ninguém seja um instrumento de uma máquina de governo.

Essa máquina de governo detém um Estado aliado ao capital, mas que padece de crescente superação pelo capital tendo em vista as mudanças decorrentes na segunda metade do século XX. O desenvolvimento da tecnologia e da pesquisa científica aprofunda-se a partir da década de 1970 com consequências e transformações para a economia mundial. O setor industrial e o setor de serviços adaptam-se para acomodar a tecnologia e a pesquisa científica a fim de contribuir para a produção e o consumo de bens e serviços. As empresas direcionam, assim, investimentos para se integrar com o setor financeiro e, com isso, se tornam conglomerados e transnacionais. O capital requer a multiplicação e o deslocamento a fim de que a integração setor industrial e setor de serviços, principalmente o financeiro, possibilite a viabilidade de uma globalização de produção e consumo. Para isso, a eliminação de fronteiras e superar o controle político e jurídico do Estado são essenciais para o capital multiplicado e o deslocamento do capital realizem-se de modo contínuo e crescente.

A velocidade como princípio filosófico contribui para lidar com elementos econômicos e sociais a fim de conceber a relação entre velocidade e capital na

\footnotetext{
18 Tradução do autor. O original é "International capital markets are alleged to have created a web of economic interdependence that has transformed the nature of international affairs and destroyed the economic and political independence of nation-states".
} 
condição de necessidade para o capital multiplicado e o deslocamento do capital. Paul Virilio institui a dimensão da distância-velocidade em que a velocidade é a medida tanto para o tempo quanto para o espaço. Igualmente, o espaço traceja-se como superado por um tempo instantâneo no marco da distância-velocidade. $\mathrm{O}$ capital multiplicado e o deslocamento do capital, portanto, estão condicionados pela dimensão da distância-velocidade concomitantemente que não podem ser controlados pelo Estado e ser distribuídos socialmente. A velocidade e a instantaneidade são essenciais ao capital multiplicado e ao deslocamento do capital em conjunto com a manutenção e o aprofundamento de diferenças entre trabalhador e investidor, entre rentistas e assalariados, entre capital intelectual e analfabetos digitais e não digitais.

O processo tecnológico somado ao capital multiplicado e ao deslocamento do capital capturam, desse modo, o ser humano, cujo padecer é um mal-estar contemporâneo com doenças e sofrimentos físicos e psíquicos. O desafio humano é existencial em como lidar com o capital e a tecnologia e em como se absorve a velocidade de uma instantaneidade em que a tecnologia se integra ao ser humano no trabalho e no modo de vida. Ao mesmo tempo, o Estado direciona-se para organização político-administrativa de um governo de ninguém a ponto de que o público não seja mais o alguém e, sim, o ninguém. O Estado vincula-se à tecnologia para viabilizar o governo de ninguém em um aprofundamento da dependência para com a economia, o capital, em que a consequência é a economia superar a política na estrita dimensão de ninguém suprimir o alguém.

\section{Referências}

ARENDT, Hannah. A condição humana. Rio de Janeiro: Forense Universitária, 2010.

ARENDT, Hannah. Entre o passado e o futuro. São Paulo: Perspectiva, 2014.

ARENDT, Hannah. Origens do totalitarismo. São Paulo: Companhia das Letras, 1989.

ARENDT, Hannah. Eichmann em Jerusalém. São Paulo: Companhia das Letras, 1999.

ARRIGHI, Giovanni. O longo século $X X$ : dinheiro, poder e as origens de nosso tempo. 1 ed. São Paulo: Editora UNESP, 1996. 
CECCHETTI, Stephen G.; KHARROUBI, Enisse. Why does financial sector growth crowd out real economic growth?. Basel: BIS, 2015. Disponível em: https://www.bis.org/publ/work490.pdf

CORTÉS, Olga Nancy P. A inter-relação bourdieusiana: habitus, campo e capital. Porto Alegre: Editora Fi, 2016.

DOWBOR, Ladislau. A era do capital improdutivo: Por que oito famílias tem mais riqueza do que a metade da população do mundo?. São Paulo: Autonomia Literária, 2017.

FELDENS, Aray Miguel. Mercado de Fatores de Produção. In: SOUZA, Nali Jesus de (Coord.). Introdução à economia. São Paulo: Atlas, 1996. p. 137-159.

FOUCAULT, Michel. Vigiar e punir: nascimento da prisão. Petrópolis: Editora Vozes, 2014.

GILPIN, Robert. Global political economy: understanding the international economic order. New Jersey: Princeton University Press, 2001.

HOBSBAWM, Eric. Era dos extremos: o breve século XX 1914-1991. São Paulo: Companhia das Letras, 1995.

KISSINGER, Henry. Does America Need a Foreign Policy?: Toward a Diplomacy for the $21^{\text {st }}$ Century. Nova York: Simon \& Schuster, 2001.

PIKETTY, Thomas. O Capital no século XXI. Rio de Janeiro: Intrínseca, 2014.

PIKETTY, Thomas. Capital e Ideología. Barcelona: Ediciones Deusto, 2019.

ROCHA, Maria Carolina dos Santos. Da dromologia: Paul Virilio e a poética do movimento. 2001. Tese (Doutorado em Filosofia) - Universidade Federal do Rio Grande do Sul, Porto Alegre, 2001.

ROSA, Hartmut. Aceleração: a transformação das estruturas temporais na Modernidade. São Paulo: Editora Unesp, 2019.

SANTOS, Milton. Metamorfosis del espacio habitado. Barcelona: Oikos-Tau, 1996.

SANTOS, Milton. Por uma outra globalização: do pensamento único à consciência universal. Rio de Janeiro: Record, 2005.

SISON, Alejo J.G. Tiempo, capital y capital humano. In: ALVIRA, Rafael; GHIRETTI, Héctor; HERRERO, Montserrat (Eds.). La experiencia social del tiempo. Pamplona: EUNSA, 2006. p. 213-236.

VIRILIO, Paul. Bunker Archéologie. Paris: Centre Georges Pompidou, 1975.

VIRILIO, Paul. L’Espace Critique. Paris: Christian Bourgois Editeur, 1984.

VIRILIO, Paul. La bomba informática. Madrid: Cátedra, 1999. 
VIRILIO, Paul. O resto do tempo. Revista Famecos: mídia, cultura e tecnologia, Porto Alegre, v. 6, n. 10, p. 57-61, jun. 1999.

VIRILIO, Paul. Velocidad y Política. Buenos Aires: La marca editora, 2006.

VIRILIO, Paul. El cibermundo, la política de lo peor. Madrid: Cátedra, 1999.

ZUBOFF, Shoshana. The Age of Surveillance Capitalism: the fight for a human future at the new frontier of power. New York: Hachette Book Group, 2019.

Recebido em: 21/07/2020. Aprovado em: 23/09/2020. Publicado em: 03/11/2020. 